Agrotrópica 33(2): 143 - 148. 2021.

Centro de Pesquisas do Cacau, Ilhéus, Bahia, Brasil

\title{
ÁCIDO GIBERÉLICO NA GERMINAÇÃO DE SEMENTES E DESENVOLVIMENTO INICIAL DE PLÂNTULAS DE MAMOEIRO
}

\author{
Marcus Vinicius Sandoval Paixão, Rafaela Barreto Cazaroto Grobério, Ana Cecília \\ Nepomuceno Hoffay, Angélica Couto Correa, Gustavo Miranda Cremonini
}

\author{
Instituto Federal de Ciência e Tecnologia do Espírito Santo - IFES Campus Santa Teresa, ES, Brasil., Santa Teresa, ES, \\ 29660.000,mvspaixao@gmail.com; rafaelacazaroto@gmail.com;ceciliahoffayagro@gmail.com; \\ angelicacoutocorrea@gmail.com; gustavom.cremonini@gmail.com
}

\begin{abstract}
As sementes de mamão apresentam dormência pós-colheita dificultando a propagação. Métodos para superar a dormência destas sementes têm sido testados, com destaque para os reguladores de crescimento. Objetivou-se avaliar o efeito do ácido giberélico na germinação e desenvolvimento inicial de plântulas de mamoeiro. O experimento foi conduzido no Laboratório de Propagação de Plantas do Instituto Federal do Espírito Santo, Campus Santa Teresa com a variedade Formosa. As sementes foram imersas por 30 minutos em água pura como testemunha e em diferentes doses de ácido giberélico e submetidas aos tratamentos com solução de giberelina $1.000 \mathrm{mg} \mathrm{L}^{-1}, 2.000 \mathrm{mg}$ $\mathrm{L}^{-1}, 3.000 \mathrm{mg} \mathrm{L}^{-1}, 4.000 \mathrm{mg} \mathrm{L}^{-1}$, colocadas para germinar em papel Germitest ${ }^{\mathbb{R}}$, em câmara tipo B.O.D. a $25^{\circ} \mathrm{C}$, luminosidade 12/12 horas. Durante 30 dias, foi avaliada a porcentagem de germinação; índice de velocidade de germinação; tempo médio de germinação. Após 60 dias do início da germinação da primeira semente, foram avaliadas: número de folhas; comprimento da raiz; altura da parte aérea; massa verde das folhas; massa seca das folhas; massa verde da raiz; massa seca da raiz, sendo selecionadas aleatoriamente para avaliação dez plantas por repetição em cada tratamento. O ácido giberélico respondeu positivamente na germinação das sementes e desenvolvimento das plântulas de mamoeiro, sendo que, a dosagem de GA3 $2.000 \mathrm{mg} \mathrm{L}^{-1}$ pode ser recomendada para a cultura.
\end{abstract}

Palavras-chave: Mamão, dormência, reguladores.

Giberelic acid in seed germination and initial development of papaya seedlings. Papaya seeds have postharvest dormancy, making sexual propagation difficult. Methods to overcome the dormancy of these seeds have been tested, with emphasis on the use of growth regulators. The objective was to evaluate the effect of gibberellic acid on the germination and initial development of papaya seedlings. The experiment was conducted at the Plant Propagation Laboratory of the IFES Campus Santa Teresa with the beautiful variety. The seeds were immersed for 30 minutes in natural water and different doses of gibberellic acid, and submitted to treatments gibberellin solution $1,000 \mathrm{mg} \mathrm{L}^{-1}, 2,000 \mathrm{mg} \mathrm{L}^{-1}, 3,000 \mathrm{mg} \mathrm{L}^{-1}, 4,000 \mathrm{mg} \mathrm{L}^{-1}$, placed to germinate on germitest paper, BOD chamber at $25^{\circ} \mathrm{C}$, brightness $12 / 12$ hours. For thirty days, the germination percentage was evaluated; germination speed index; average germination time. Sixty days after germination of the first seed, the following were evaluated: number of leaves; root length; aerial part height; green leaf mass; dry leaf mass; green root mass; dry root mass, with ten plants per replication being randomly selected for each treatment. Gibberellic acid responded positively in germination of seeds and development of papaya seedlings, and the dosage of GA3 2,000 mg L-1 can be recommended for culture.

Key words: Papaya, numbness, regulators. 


\section{Introdução}

O Brasil está entre os grandes produtores de mamão do mundo, tendo registrado em 2019 uma produção de 1.161.808 toneladas em uma área de 27.556 ha, sendo que os estados da Bahia e do Espírito Santo concentram a maior parte da produção brasileira (IBGE, 2019).

As sementes de mamão apresentam dormência pós-colheita dificultando a propagação sexuada. Alguns métodos para superar a dormência destas sementes têm sido testados, com destaque para o uso de baixa temperatura; envelhecimento acelerado; lavagem em água corrente; remoção da sarcotesta; aplicação de KNO3, de hipoclorito de sódio, uso de reguladores de crescimento; dentre outros (Tokuhisa et al., 2007).

Se considerarmos que entre três a quatro anos os plantios de mamoeiro têm de ser renovados, a demanda por sementes passa a ter maior valor e sua qualidade passa a ser de grande importância para a melhoria da cultura no país.

Diversos são os fatores que controlam o processo de germinação, dentre eles os níveis endógenos de hormônios, responsáveis pelas alterações no estado fisiológico e bioquímico que levam na retomada do desenvolvimento embrionário, sendo que estas alterações são responsáveis pela ativação e síntese de enzimas hidrolíticas, quebrando as moléculas de reservas utilizadas para o crescimento do eixo embrionário (Marcos Filho, 2015). Desta forma, o processo de mobilização de reservas em sementes tem participação direta dos hormônios.

Para que o processo de germinação ocorra de forma mais uniforme e com maior percentual possível, têmse alguns procedimentos que podem ser adotados nas sementes, como a identificação adequada de temperatura ambiente, a aplicação de reguladores vegetais (Ferrari et al., 2008), e o uso de técnicas para acelerar a embebição da semente.

Rodriguéz et al. (2013) citam que a germinação da semente de mamão é considerada lenta e irregular, esta causada pela presença de sarcotesta nas sementes, assim como a existência de dormência associada a maturação e época de colheita dos frutos.

Substâncias inibidoras têm papel altamente relevante no processo de germinação das sementes (Manica, 1982). Embora tais substâncias inibidoras não sejam totalmente identificadas pelos pesquisadores, atribui-se a elas a regulação da germinação, pois, estas substâncias podem estar presentes tanto na sarcotesta quanto na esclerotesta (Hoffay et al., 2018).

As giberelinas são sintetizadas principalmente no ápice caulinar e nas folhas jovens em desenvolvimento, assim como nos entrenós jovens e em crescimento ativo, atuando principalmente na quebra de dormência de sementes que requerem luz ou frio para a indução da germinação, enfraquecimento da camada do endosperma que envolve o embrião e restringe o seu crescimento, na produção de enzimas (á-amilase e outras enzimas hidrolíticas), na mobilização de reservas energéticas do endosperma e na ativação do crescimento vegetativo do embrião (Paixão, 2019).

A ação da giberelina está relacionada à síntese de enzimas envolvidas no enfraquecimento dos tegumentos, como endo-â-manases, sendo expansivas e de enzimas hidrolíticas de reserva nutritiva contida no endosperma, como á-amilase (Paixão, 2019). Esses eventos estão relacionados ao alongamento embrionário e à protrusão da radícula permitindo a quebra do amido e consequente liberação de energia e posteriormente a retomada do crescimento do embrião, gerando em seguida a protusão da radícula (Ferreira et al., 2005).

Na germinação das sementes temos hormônios que atuam como promotores e como inibidores. As giberelinas estão entre os promotores da germinação, estas atuam no crescimento vegetativo do embrião, mobilizando reservas e enfraquecendo o endosperma que cobre o embrião e bloqueia seu crescimento (Taiz et al., 2017). Encontrado em várias partes das plantas, como, raízes, folhas jovens, sementes em fase de germinação e nos frutos (Lavagnini et al., 2014), sua atuação está relacionada ao preparo, sendo importante a concentração, o número de aplicações, a época de aplicação e a espécie ou cultivar em uso (Wagner Júnior et al., 2012).

As giberelinas, como o ácido giberélico (GA3), aumentam a elongação e divisão celular, o que é evidenciado pelo aumento do comprimento e do número de células em resposta à aplicação deste fitorregulador (Taiz e Zeiger, 2013).

A pesquisa foi realizada com o objetivo de avaliar o efeito do ácido giberélico na germinação e desenvolvimento inicial de plântulas de mamoeiro. 


\section{Material e Métodos}

O experimento foi conduzido no Laboratório de Propagação de Plantas do Instituto Federal do Espírito Santo, Campus Santa Teresa. A variedade utilizada para o experimento foi à Formosa, sendo as sementes imersas por 30 minutos em água pura como testemunha e em diferentes doses de ácido giberélico, submetidas aos tratamentos com solução de giberelina $1.000 \mathrm{mg} \mathrm{L}^{-1}, 2.000 \mathrm{mg} \mathrm{L}^{-1}, 3.000 \mathrm{mg} \mathrm{L}^{-1}, 4.000 \mathrm{mg} \mathrm{L}^{-}$ ${ }^{1}$, colocadas para germinar em papel Germitest ${ }^{\mathbb{R}}$ umedecidas com 2,5 vezes o peso do papel, em câmara tipo B.O.D. a $25^{\circ} \mathrm{C}$, luminosidade $12 / 12$ horas.

$\mathrm{O}$ experimento foi preparado em delineamento inteiramente casualizado (DIC), com cinco tratamentos e quatro repetições, sendo que cada unidade experimental foi composta por 100 sementes.

Após a germinação da primeira semente e durante trinta dias, foi avaliada a porcentagem de germinação (G); índice de velocidade de germinação (IVG); tempo médio de germinação (TMG).

Após Sessenta dias do início da germinação da primeira semente, foram avaliadas as variáveis: número de folhas (NF); comprimento da raiz (CR); altura da parte aérea (AP); massa verde das folhas (MVF); massa seca das folhas (MSF); massa verde da raiz (MVR); massa seca da raiz (MSR), sendo selecionadas aleatoriamente para avaliação dez plantas por repetição em cada tratamento.

Os dados obtidos foram submetidos à análise de variância, atendendo pressuposições do modelo pelo teste de Shapiro-Wilk para verificação da normalidade e as médias dos tratamentos foram comparadas pelo teste de Tukey em nível de $5 \%$ de probabilidade e análise de regressão para as variáveis que apresentaram significância, utilizando o programa $\mathrm{R}$.

\section{Resultados e Discussão}

A germinação iniciou aos nove dias após a semeadura nos tratamentos com giberelina, sendo que na testemunha a germinação iniciou aos 24 dias. De acordo com a Tabela 1, o ácido giberélico teve influência na germinação da semente de mamão, com valores superiores a testemunha. As dosagens de 2.000 $\mathrm{mg} \mathrm{L}^{-1} \mathrm{e} 3.000 \mathrm{mg} \mathrm{L}^{-1}$ apresentaram valores estatisticamente superiores a testemunha, sendo que o aumento da concentração de giberelina não atuou de forma positiva na germinação. As dosagens de $2.000 \mathrm{mg} \mathrm{L}^{-1} \mathrm{e} 3.000 \mathrm{mg} \mathrm{L}^{-1}$ não apresentaram diferença estatística, porém as avaliações para a dosagem de $2.000 \mathrm{mg} \mathrm{L}^{-1}$ foram sempre superiores numericamente.

Para a velocidade de germinação e tempo de germinação, a dosagem de $2000 \mathrm{mg} \mathrm{L}^{-1}$ apresentou a maior velocidade e o menor tempo de geminação, porém sem diferença estatística significativa para as dosagens de $3.000 \mathrm{mg} \mathrm{L}^{-1}$ e $4.000 \mathrm{mg} \mathrm{L}^{-1}$ (Tabela 1).

Sousa et al. (2008) encontraram os melhores resultados com o uso de ácido giberélico a 50 e 750 $\mathrm{mg} \mathrm{L}^{-1}$ embebidos por 12 horas, em sementes de pinha sendo que, a baixa concentração de giberelina foi compensada pelo tempo de exposição da semente ao hormônio.

A testemunha apresentou baixa germinação (45\%) em relação aos tratamentos com giberelina, semelhante ao encontrado por Zanotti et al. (2011) que encontraram médias de $43 \%$ de germinação, comprovando a existência de dormência nestas sementes.

Lopes et al. (2009) utilizando a imersão de sementes de frutos maduros não obtiveram germinação para sementes sem tratamento $(\mathrm{G}=0 \%)$, sendo que as sementes que foram imersas em solução de giberelina $1.000 \mathrm{mg} \mathrm{L}^{-1}$ promoveram melhor germinação $(67,75 \%)$, semelhante ao encontrado neste trabalho (69\%), com maior desenvolvimento das plântulas, porém estes autores não testaram dosagens maiores, o que poderia alterar os seus resultados.

De acordo com a análise de regressão (Figura 1), o valor ideal para a dosagem de giberelina tramita entre $2000 \mathrm{mg} \mathrm{L}^{-1}$ e $3000 \mathrm{mg} \mathrm{L}^{-1}$, considerando que estas dosagens são muito pequenas quando se realizou os

Tabela 1 - Germinação em sementes de mamão submetidas a diferentes doses de GA3

\begin{tabular}{llll}
\hline \multicolumn{1}{c}{ Tratamento } & G $(\boldsymbol{\%})$ & IVG & TMG \\
\hline Testemunha & $45 \mathrm{~b}$ & $0,565 \mathrm{c}$ & $24,330 \mathrm{~b}$ \\
GA3 1000 mg L & $69 \mathrm{ab}$ & $0,940 \mathrm{~b}$ & $20,901 \mathrm{~b}$ \\
GA3 2000 mg L & $86 \mathrm{a}$ & $1,675 \mathrm{a}$ & $14,796 \mathrm{a}$ \\
GA3 3000 mg L-1 & $85 \mathrm{a}$ & $1,671 \mathrm{a}$ & $15,021 \mathrm{a}$ \\
GA3 4000 m L L $^{-1}$ & $68 \mathrm{ab}$ & $1,415 \mathrm{a}$ & $14,965 \mathrm{a}$ \\
\hline
\end{tabular}

Médias, seguidas das mesmas letras nas colunas são estatisticamente iguais pelo teste de Tukey em 5\% de probabilidade. $\mathrm{G}=$ germinação; $\mathrm{IVG}=$ índice de velocidade de germinação; TMG = tempo médio de germinação. 
tratamentos das sementes, permitindo considerar que a menor dosagem é economicamente a dosagem viável para a germinação de sementes de mamão, visto que também o IVG e TMG apresentaram os mesmos resultados (Figuras 2 e 3).

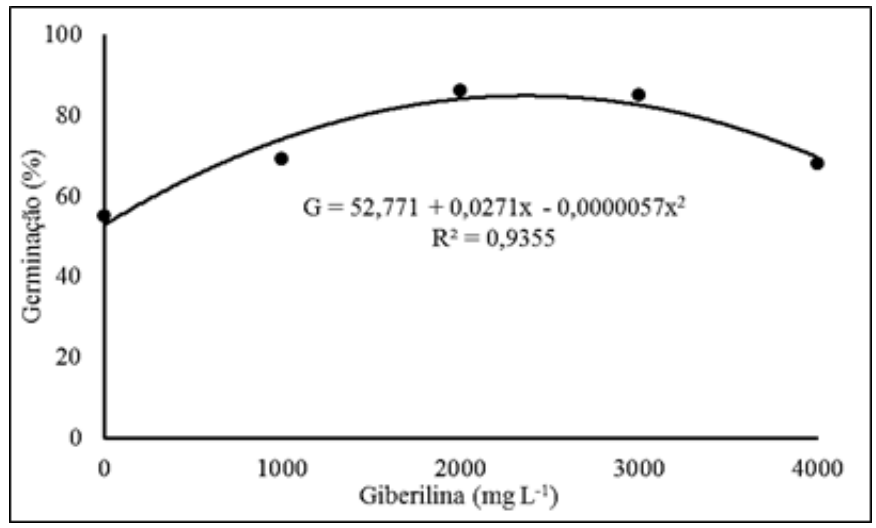

Figura 1 - Regressão para germinação $(\mathrm{G})$.

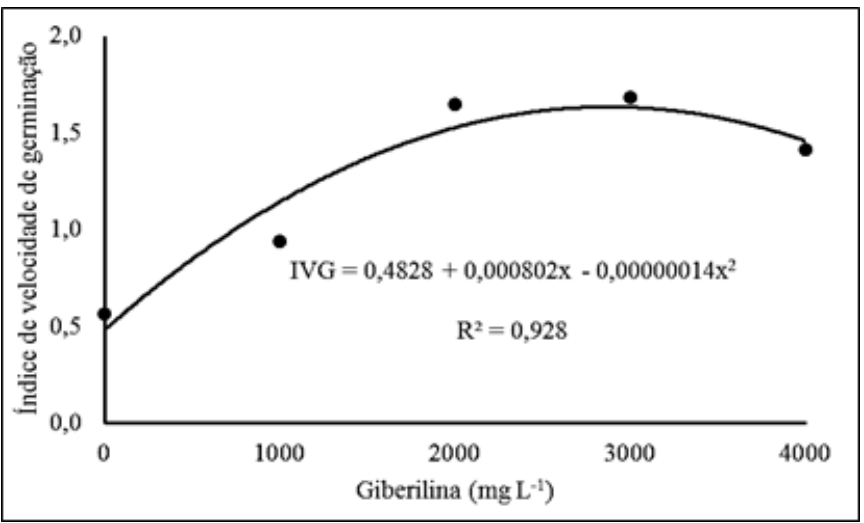

Figura 2 - Regressão para Índice de velocidade de germinação (IVG).

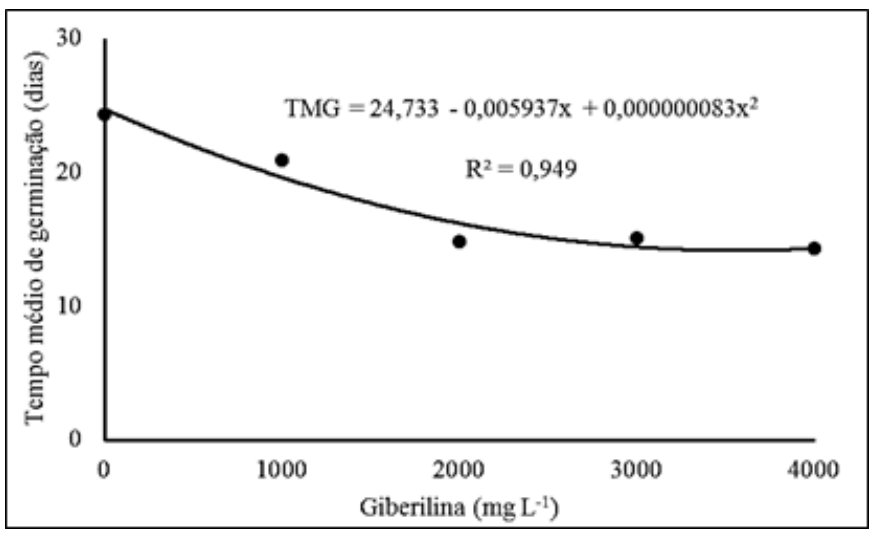

Figura 3 - Regressão tempo médio de germinação (TMG)
Os resultados observados no presente trabalho mostram que a semente de mamão possui dormência, porém, para que haja germinação é necessário que primeiro ocorra à síntese de GA3 no embrião, o que exige energia (ATP) oriunda de processos respiratórios e água para ativar a referida rota. Neste trabalho, o uso de giberelina apresentou melhoras na germinação, velocidade e tempo para germinar. A pesquisa mostra que imergir as mesmas em solução de giberelina por trinta minutos é o suficiente para reestimular o início do desenvolvimento do embrião, para aumentar a germinação, acelerar e diminuir o tempo de germinação.

De acordo com a Tabela 2 o ácido giberélico teve influência no desenvolvimento inicial das plântulas de mamoeiro, com valores superiores a testemunha. A dosagem de $2.000 \mathrm{mg} \mathrm{L}^{-1}$ apresentou valores estatisticamente superiores a testemunha e aos demais tratamentos com giberelina, sendo que o aumento da concentração de giberelina não atuou de forma positiva na germinação.

A giberelina atua na fase de germinação das sementes melhorando o desenvolvimento inicial das plântulas, realçando o seu potencial (Lopes et al., 2009). A melhora no desenvolvimento está relacionada à ação da giberelina na produção que enzimas hidrolíticas, as quais quebram o amido e outras substâncias, permitindo a retomada do crescimento do eixo embrionário.

Sousa et al. (2008) encontraram os melhores resultados com o uso de ácido giberélico a 50 e 750 mg L ${ }^{-1}$ embebidos por 12 horas, em sementes de pinha. Neste caso, a baixa concentração de giberelina foi compensada pelo tempo de exposição da semente ao hormônio.

Alguns autores também encontraram resultados positivos com uso de giberelina, Braun et al. (2010) com Beta vulgaris L.; Oliveira et al. (2010) com atemoia (Annona cherimola Mill. x Annona squamosa L.); Peixoto et al. (2011) com Ricinus communis L. e Silva et al. (2013) com B. brizantha "Marandu" e "MG 5", que observaram a quebra da dormência de sementes em diversas espécies vegetais tratadas com giberelinas.

Lopes et al. (2009) observaram que para a massa verde e para a massa seca de dez plântulas, 
Tabela 2 - Desenvolvimento de plântulas de mamoeiro submetidas a diferentes doses de GA3

\begin{tabular}{lccccccc}
\hline \multicolumn{1}{c}{ Tratamento } & NF & AP & CR & MVF & MSF & MVR & MSR \\
\hline Testemunha & $1,80 \mathrm{~b}$ & $4,31 \mathrm{c}$ & $4,83 \mathrm{~b}$ & $0,029 \mathrm{~b}$ & $0,004 \mathrm{~d}$ & $0,021 \mathrm{c}$ & $0,004 \mathrm{~b}$ \\
GA3 $1000 \mathrm{mg} \mathrm{L}^{-1}$ & $2,35 \mathrm{~b}$ & $9,28 \mathrm{~b}$ & $5,93 \mathrm{ab}$ & $0,078 \mathrm{a}$ & $0,016 \mathrm{~b}$ & $0,041 \mathrm{~b}$ & $0,008 \mathrm{~b}$ \\
GA3 2000 $\mathrm{mg} \mathrm{L}^{-1}$ & $3,85 \mathrm{a}$ & $13,34 \mathrm{a}$ & $8,31 \mathrm{a}$ & $0,097 \mathrm{a}$ & $0,024 \mathrm{a}$ & $0,095 \mathrm{a}$ & $0,032 \mathrm{a}$ \\
GA3 3000 $\mathrm{mg} \mathrm{L}^{-1}$ & $2,39 \mathrm{~b}$ & $11,11 \mathrm{ab}$ & $7,35 \mathrm{ab}$ & $0,085 \mathrm{a}$ & $0,018 \mathrm{~b}$ & $0,043 \mathrm{~b}$ & $0,010 \mathrm{~b}$ \\
GA3 4000 $\mathrm{mg} \mathrm{L}^{-1}$ & $2,30 \mathrm{~b}$ & $5,76 \mathrm{c}$ & $7,24 \mathrm{ab}$ & $0,040 \mathrm{~b}$ & $0,010 \mathrm{c}$ & $0,039 \mathrm{~b}$ & $0,008 \mathrm{~b}$ \\
\hline
\end{tabular}

Médias, seguidas das mesmas letras nas colunas são estatisticamente iguais pelo teste de Tukey em $5 \%$ de probabilidade.

$\mathrm{NF}=$ número de folhas; $\mathrm{AP}=$ altura da planta $(\mathrm{cm}) ; \mathrm{CR}=$ comprimento da raiz $(\mathrm{cm}) ; \mathrm{MVF}=$ massa verde das folhas $\left(\mathrm{g} \cdot \mathrm{pl}^{-1}\right)$; $\mathrm{MSF}=$ massa seca das folhas $\left(\mathrm{g} \cdot \mathrm{pl}^{-1}\right) ; \mathrm{MVR}=$ massa verde das raízes $\left(\mathrm{g} \cdot \mathrm{pl}^{-1}\right) ; \mathrm{MSF}=$ massa seca das raízes $\left(\mathrm{g} \cdot \mathrm{pl}^{-1}\right)$.

houve diferença nas concentrações de GA3 de 500 $\mathrm{mg} \mathrm{L^{-1 }}$ e $1.000 \mathrm{mg} \mathrm{L}^{-1}$ e a testemunha, porém estas concentrações foram muito baixas em relações as concentrações utilizadas nesta pesquisa.

O teste de regressão apresentou dosagem ideal de giberelina próximo de $2.000 \mathrm{mg} \mathrm{L}^{-1}$. Para todas as variáveis avaliadas em dosagens superiores, a tendência é de queda nos valores apurados, com perdas no desenvolvimento da plântula (Figuras 4 e 5).

O mesmo pode ser observado para a produção de massa foliar e massa das raízes, onde a regressão apresenta a tendência a perda de massa verde e massa seca das folhas, assim como a massa verde e massa seca das raízes, comprovando que valores superiores a $2.000 \mathrm{mg} \mathrm{L}^{-1}$ são prejudiciais à produção de massa ocasionando a queda no desenvolvimento das plântulas de mamoeiro (Figuras 6 e 7).

Os dados observados no presente trabalho mostram que as sementes de mamão são sensíveis ao uso de giberelina de acordo com a dosagem e tempo de imersão das sementes. Neste estudo, o uso de giberelina apresentou melhoras na germinação e no

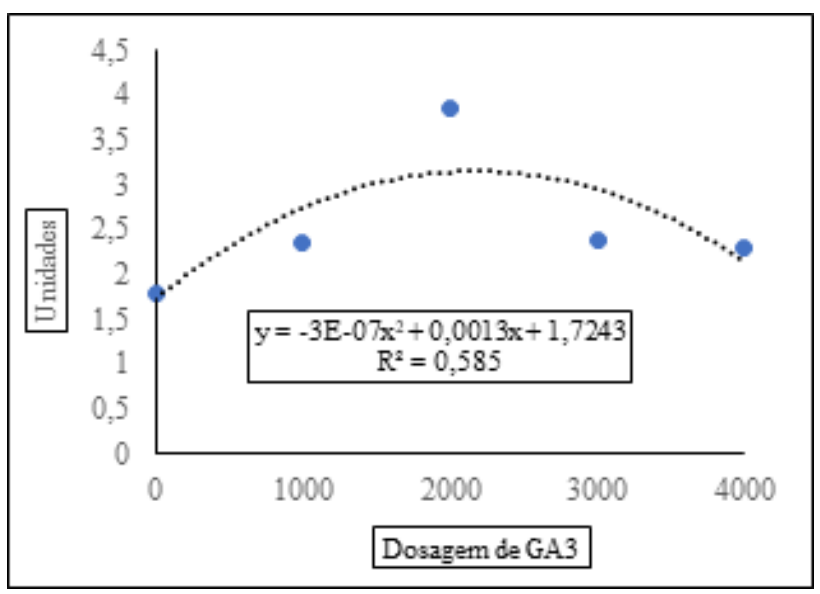

Figura 4 - Regressão para número de folhas.

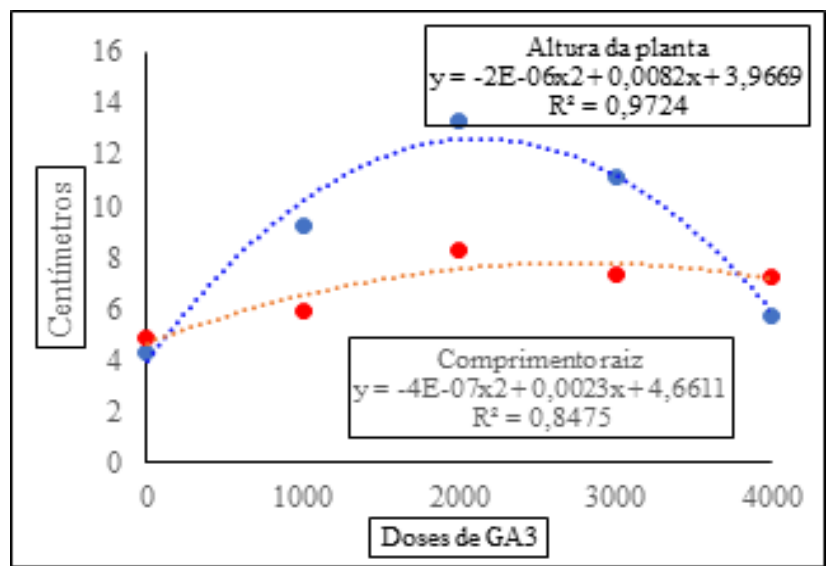

Figura 5 - Altura da planta e comprimento da raiz.

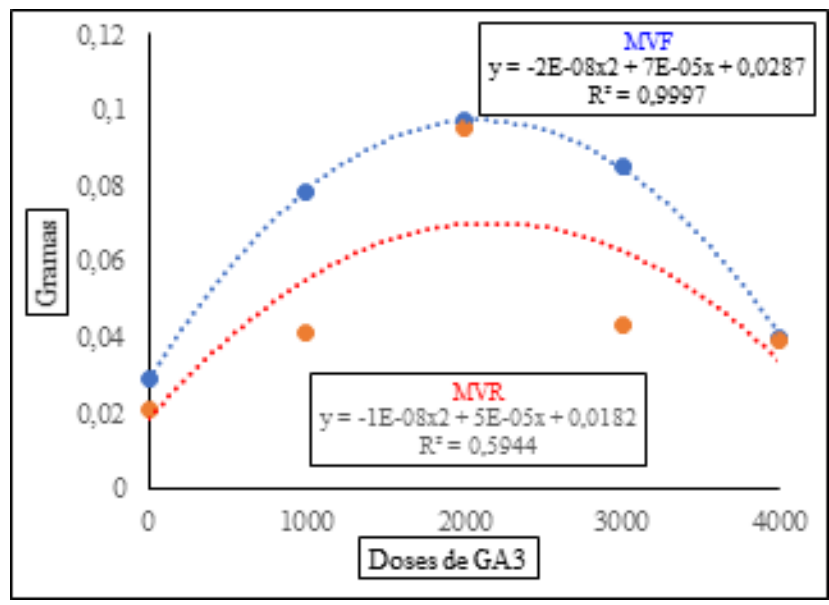

Figura 6 - Regressão para massa verde.

desenvolvimento inicial das plântulas, sugerindo que imergir as sementes em solução de giberelina por 30 minutos na dosagem de $2.000 \mathrm{mg} \mathrm{L}^{-1}$ foi suficiente para reestimular o início do desenvolvimento do embrião, promovendo o alongamento celular e melhorar seu desenvolvimento inicial. 


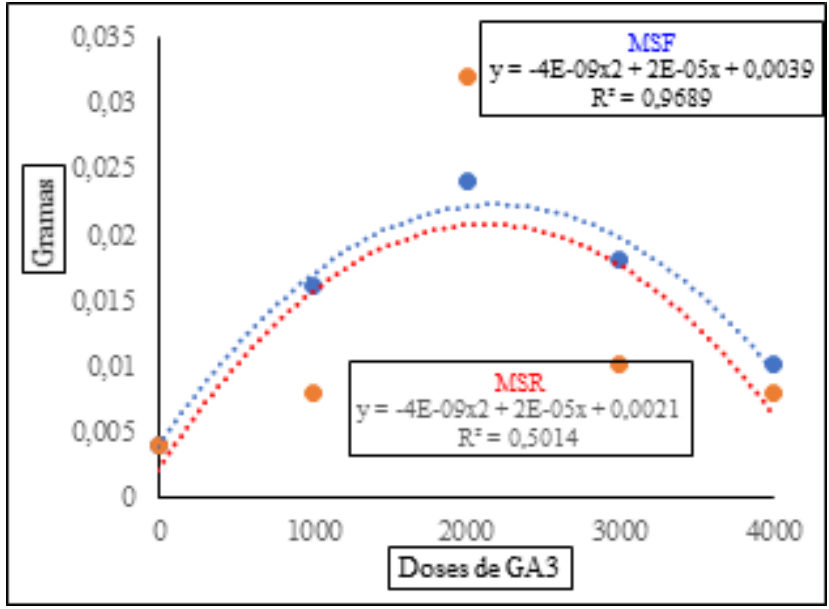

Figura 7 - Regressão para massa seca.

\section{Conclusão}

O ácido giberélico respondeu positivamente na germinação das sementes e desenvolvimento das plântulas de mamoeiro, sendo que, a utilização deste hormônio na dosagem de $2.000 \mathrm{mg} \mathrm{L}^{-1}$ pode ser recomendada para a cultura.

\section{Literatura Citada}

BRAUN, H. et al. 2010. Germinação in vitro de sementes de beterrabas tratadas com ácido giberélico em diferentes concentrações de sacarose no meio de cultura. Semina: Ciências Agrárias 31(3):539-546.

FERRARI, T. B. et al. 2008. Germinação de sementes de maracujá-doce (Passiflora alata Curtis): Fases e efeito de reguladores vegetais. Revista Biotemas 21(3):65-74.

FERREIRA, G. et al. 2005. Efeito de arilo na germinação de sementes de Passiflora alata Curtis em diferentes substratos e submetidas a tratamentos com giberelina. Revista Brasileira de Fruticultura 27(2):277-280.

HOFFAY, A. C. N. et al. 2018. Ácido giberélico no desenvolvimento inicial de plântulas de mamoeiro. In: Simpósio do Papaya Brasileiro, 7. Anais...

INSTITUTO BRASILEIRO DE GEOGRAFIA E ESTATÍSTICA - IBGE. Produção Agrícola Municipal, 2019. Disponível em: http:// www.cnpmf. embrapa.br/Base_de_Dados/ index_pdf/dados/brasil/mamao/b1_mamao.pdf
LAVAGNINI, C. G. et al. 2014. Fisiologia Vegetal Hormônio Giberelina. Revista Científica Eletrônica de Agronomia (FAEF) 25(1):48-52.

LOPES, A. W. P. et al. 2009. Estádio de maturação do fruto e uso do ácido giberélico na germinação de sementes de mamoeiro. Pesquisa Agropecuária Tropical 39(4):278-284.

MANICA, I. 1982. Fruticultura Tropical 3: mamão. São Paulo, SP, Ceres.

MARCOS FILHO, J. 2015. Fisiologia de sementes de plantas cultivadas, 2 ed., Londrina, PR, ABRATES. 660p.

OLIVEIRA, M. C. et al. 2010. Germinação de sementes de atemoia (annona cherimola Mill. x a. squamosa L.) cv "gefner" submetidas a tratamentos com ácido giberélico (GA3) e ethephon. Revista Brasileira de Fruticultura 32(2):544-554.

PAIXÃO, M. V. S. 2019. Propagação de plantas. 2.ed. Santa Teresa: Ifes, 230p.

PEIXOTO, C. P. et al. 2011. Ação da giberelina em sementes pré-embebidas de mamoneira. Comunicata Scientiae 2(2):70-75.

RODRÍGUEZ, J. A. R. et al. 2013. Escarificación química de semilla de papaya. Revista Mexicana de Ciencias Agrícolas 4(6):47-954.

SILVA, A. B.; LANDGRAF, P. R. C.; MACHADO, G. W. O. 2013. Germinação de sementes de braquiária sob diferentes concentrações de giberelina. Semina: Ciências Agrárias 34(2):657-662.

SOUSA, S. A. et al. 2008. Superação da dormência em sementes de pinha. Caatinga (Brasil) 21(4):118-121.

TAIZ, L.;ZEIGER, E. 2013. Fisiologia e desenvolvimento vegetal. 5.ed. Artmed editora, Porto Alegre. 918p.

TAIZ, L. et al. 2017. Fisiologia e desenvolvimento vegetal. 6.ed. Artmed editora, Porto Alegre. 888 p.

TOKUHISA, D. et al. 2007. Tratamentos para superação da dormência em sementes de mamão. Revista Brasileira de Sementes 29(1):131-139.

WAGNER JÚNIOR, A. et al. 2012. Influência do substrato e do ácido giberélico no desenvolvimento inicial do pessegueiro progênie 290. Revista Brasileira de Agrociência (UFPEL) 18:11-20.

ZANOTTI, R. F. et al. 2011. Métodos para superação da dormência em sementes de mamão grupo formosa. In: Encontro Latino Americano de Iniciação Científica,14, e Encontro Latino Americano de PósGraduação, 10. Anais... Paraíba, SE, Universidade do Vale do Paraíba. 